\title{
Innovate Designs for Upholstery Fabrics Glow in the Dark, Inspired from Islamic Art
}

\author{
Dr. Hafez S. Hawas ${ }^{1}$, Dr. Shaimaa A. shaker ${ }^{2}$ \\ 1- Lecturer at Spinning, Weaving \& Knitting dept., Faculty of Applied Arts, Helwan University \\ 2-Lecturer at Textile Printing, Dyeing \& Finishing dept., Faculty of Applied Arts, Helwan University
}

\section{KEY WORDS:}

upholstery fabrics, Islamic Art, Photoluminescent material, glow in dark, strontium aluminate Phosphor, Textile design.

\begin{abstract}
:
This research concern on producing upholstery fabrics designs inspired from Islamic art which glowing in dark using strontium aluminate Phosphor. Photoluminescent (PL) material such as Phosphor of strontium aluminate (SrAl2O4: Eu2+, Dy3+) is a kind of energy storage material, it can absorb both ultraviolet (UV) and visible lights from the sunlight and keeps emitting light for a period of time in absence of the illumination source at a certain wave length.

The research focused on Islamic art as a source of inspiration due to its richness in the floral, geometric, written, abstract and symbolic motifs.

So that we use two pure cotton fabrics $(100 \%)$ with different operational specifications, one of them (plain 1/1) and the other sample (Basket 3/3). These fabrics were used for producing the (PL) upholstery fabrics with seven different concentrations of strontium aluminate Phosphor (SAOED) pigment ranged from (1: $7 \mathrm{wt} . \%)$ using a hand printing method to produce fourteen samples.

Our findings that there is a direct relationship between air permeability, bending length in weft \& warp direction, tensile strength, elongation and the concentrations of (SAOED). The best sample performance evaluated by radar chart for the given properties is sample (A1) with the quality factor percentage $(83.4 \%)$.

According to the quality factor test result the research team decided applied the five innovate designs inspired from islamic art with the same specification of the sample which achieved a high functional property.

The statistical analysis of the questionnaire results shows that the best design idea evaluated by radar chart (design two) with the quality factor percentage ( $86.4 \%$ ). Therefore, using strontium aluminate Phosphor is considered a technological method that enriches the aesthetics and functional properties of the upholstery fabric design
\end{abstract}




\section{INTRODUCTION:}

The efficiency of balanced between the aesthetic and functional properties of designing and producing upholstery fabrics is the essential target for textile designers(1). upholstery fabrics design is considered one of the most important fields on the textile's world, where upholstery fabric plays a large role in creating the style of the furniture it covers.

Islam has given the art of ornamentation a special significance, where its re-shaped forms of nature and processed them by using several procedures such as transformation, simplification and reduction, due to the importance of floral and geometric elements that characterized(2). The geometric motifs that were built on the idea of abstraction (3), a core element in islamic faith which had a great role in its existence as a style. Islamic art applied abstract geometrical shapes and lines such as perpendicular lines, squares, rectangles, triangles, circles and alternating polygons resulting from the intersections, to create extended rhythmic designs of simple geometry(4).

The islamic art of ornamentation originates from the creation of a first simple form of a single unit "the origin", then it is followed by multiple repetitive schemes in different directions so that they reproduce with a synaptic system, and those units move from the simulation of nature to abstraction(5). This means to abandon precise mimic of nature, summing up elements, filling and eliminating the spaces and covering all the surfaces of the work with decorative elements(6). Figure (1) shows the example of islamic art element or decorative canons which are the Arabesque, Geometric and Calligraphy.
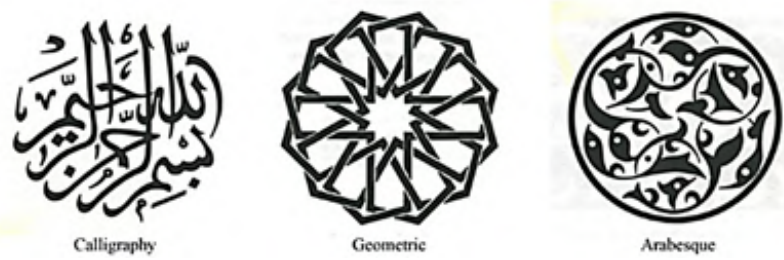

Fig. (1) Islamic Art Elements

The use of Photoluminescent materials in textiles design can offer innovative opportunities to accomplish aesthetic and functional properties in produced fabric. These materials have been used in a wide range of applications for embroidery or sewing threads, toy fabric, protective clothing for fire-fighters and chemical workers, furniture and decoration, ropes and cords, tents, carpets and curtains etc. (7) There are several kinds of photoluminescent materials available commercially(8).Organic compounds such as porphyrins and perylenes or inorganic materials as SrA12O4:Eu2+, Dy3+(9).

Up to now, there are different long-lasting luminescent materials have been developed as different primary color emitters, such as SrMgSi2O6:Eu2+/Dy3+ or CaA12O4:Eu2+/Nd3+ for blue, SrAl2O4:Eu2+/ $\mathrm{Dy} 3+$ or MgAl2O4:Mn2+ for green and CaS:Eu2+/ $\mathrm{Tm} 3+/ \mathrm{Ce} 3+$ or $\mathrm{Y} 2 \mathrm{O} 2 \mathrm{~S}: \mathrm{Eu} 3+, \mathrm{Mg} 2+/ \mathrm{Ti} 4+$ for red. (9) Phosphor of strontium aluminate co-active by Eu2+ and Dy $3+$ is one kind of important photoluminescent materials(10). due to its higher brightness, longer persistence time (>10 h), with photo, chemical and physical stabilities(11). Luminescence is the spontaneous emission of light from the excited electronic states of physical systems. The emission is preceded by the process of excitation, which may be produced by a variety of agents. If it is achieved by the absorption of light it is called photoluminescence, if by the action of an electric field electroluminescence, if by achemical reaction chemiluminescence, and so on(12). Figure (2) shows Principle of photoluminescence.

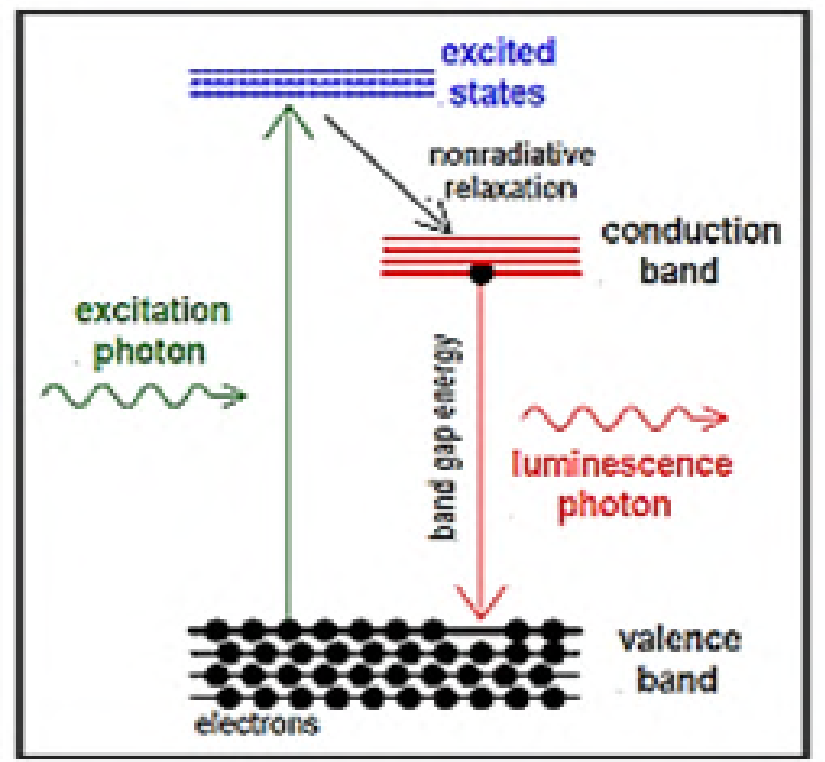

Fig. (2) Principle of photoluminescence

\section{Materials and Methods:}

The main purpose of the present study is divided into three parts: Firstly, Produce Photoluminescent (PL) upholstery fabrics which glowing in the dark, using a stencil printing method and evaluating the quality factor of this samples to determine the best sample which 
fulfill the functional performance it is produced for. Secondly, Applied the innovate designs inspired from Islamic art with the same specification of the sample which achieved a high functional property according to the quality factor ranking, and finallydesigning a questionnaire to evaluate the innovative designs by some of specialists in textile field and non-specialists in order to get their views all scientific, technical and marketing. where the questionnaire included several questions:

-Appropriateness of the forms (formative elements) of the design idea.

-The consistency of colors with the design idea.

-The extent to lighting clarity for night design

-The effect of night lighting on the aesthetic and functional value of the design

-Appropriateness of the design idea for the proposed recruitment.

\subsection{Produce Photoluminescent (PL) upholstery fabrics}

\subsubsection{Specifications of produced fabrics}

The cotton fabrics $(100 \%)$ was supplied by "Vantex company", Cairo, Egypt. These fabrics were produced on a dobby weaving machines with operational specifications shown in the table (1).

Table (1) the operational specifications of the produced samples

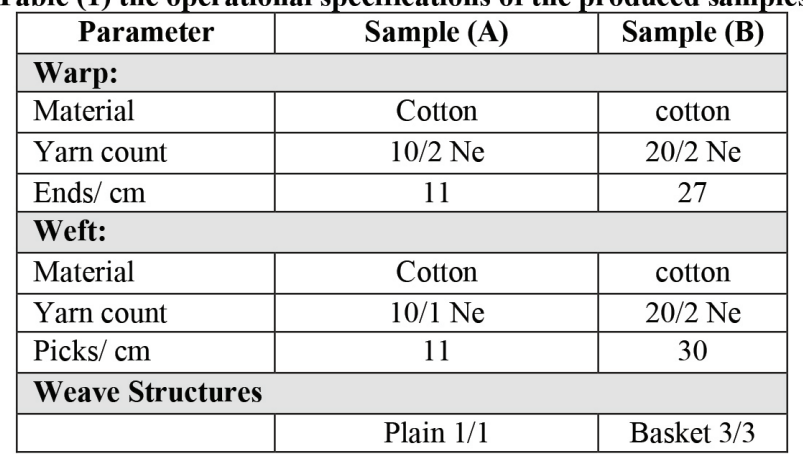

\section{* Ne: English cotton count}

\subsubsection{Producing Photoluminescent (PL) upholstery}

\section{fabrics}

The previous two cotton fabrics were used for producing the (PL) upholstery fabrics with seven different concentrations of strontium aluminate Phosphor (SAOED) pigment ranged from (1: $7 \mathrm{wt} . \%)$ using the stencil printing method. The printed (14 samples) left for sixty minutes at room temperature followed by thermal fixation at $180 \square$ for three minutes. The samples were counted as following, From (A1:A7) for the printed cotton fabric with plain 1/1 structure and from (B1:B7) for the printed cotton fabric with basket $3 / 3$ structure.

\subsubsection{Measurements and Testing}

Many different tests were carried out on samples to evaluate Physical and comfort propertiesas: tensile strength, elongation, stiffness and air permeability, then grading the samples according to quality factor.

\subsubsection{Quality factor}

The averages Results measurements of the sample's tests were converted to comparison relative values (without units) ranges from $(0 \%-100 \%)$ called quality factor, where the greatest comparative value is the best with all the properties. The following equation was used to calculate the relative comparison value (quality factor) for all the properties except the stiffness property.

$\mathrm{Q} F+=(\mathrm{X} / \mathrm{X} \max ) \times 100$

Where: Q.F (quality factor), X (reading for each sample), $X$ Max (the highest reading)

The following equation was used to calculate the relative comparison value (quality factor) for the stiffness property.

$\mathrm{Q} F-=(\mathrm{X} \min / \mathrm{X}) \times 100$

Where: Q.F (quality factor), X Min (the least reading), $\mathrm{X}$ (reading for each sample)

To calculate the total quality factor of each sample which is equivalent to the performance for each fabric the following equation was used:

Quality Factor $=(\mathrm{A}+\mathrm{B}+\mathrm{C}+\mathrm{D}+\mathrm{E}+\mathrm{F}+\mathrm{G}) / 7$

Where: $(\mathrm{A}, \mathrm{B}, \ldots ., \mathrm{G})$ refer to evaluated properties

\subsubsection{Colorfastness to rubbing}

This test was carried out on the sample which achieved a high functional property by using (SDL ATLAS Tester) according to Standard Specification of (ISO 105$\mathrm{X} 12)(14)$.

\subsubsection{Colorfastness to washing}

This test was carried out on the sample with high functional propertiesaccording to Standard Specification of (ISO 105-C02)(15).

\subsection{Applied the innovate designs inspired from Is- lamic art}

According to the quality factor test result the research team decided applied the innovate designs inspired from islamic art with the same specification of the sample which achieved a high functional property. The following part present the five designing ideas inspired of organic, geometric, and calligraphic patterns from Islamic art which were printed on fabric with pigment colors and one color of photo-luminescent pigment using Stencil printing method. 
2.2.1 Design Idea no. (1):Depends on using an irregular repetition of Islamic geometric elements. this diversity and difference in the lines values and designing units would generate to the recipient the sense of permanent movement and diversity. There is distribution for the idea's elements to be compatible with the idea of employed it as curtains fabrics.

The color: The colors have been diversifying between warmth and coolness which gives unity and balance in general, also transparency colors, lights and shadows played an important role in showing the beauty of each element separately.
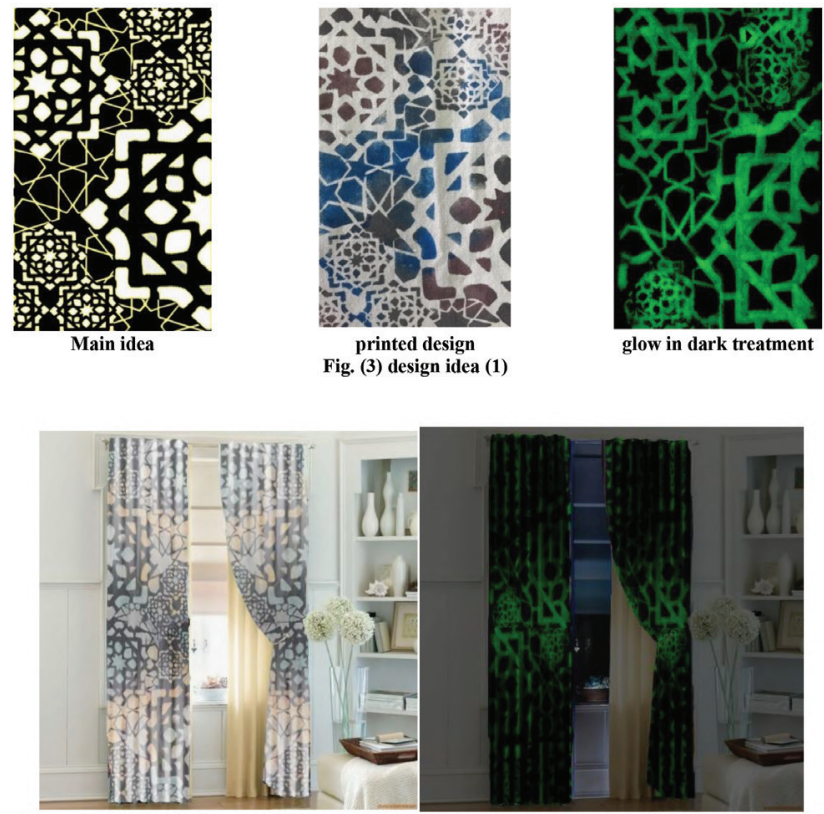

Fig. (4)Illustration of the 3D-simulation for Design (1)

2.2.2. Design Idea no. (2): depends on inspiring a group of regular islamic geometric shapes that interlaced and correlated with each other creating accurate geometric background, which lead to achieve the unity in the design by limiting the subject's key elements within the framework.

The color: In the printed design the color could contributes with an important part in organizing the visual perception between the work parts. The use of green and blue in the shape and the cream color on the ground came as a link between the work elements, and confirms the unity and balance of those elements. Also, this trilling of light and dark led to create a sort of rhythmic harmony between the work parts.

2.2.3 Design Idea no. (3):depends on the combination of plant and geometric elements that combines both rhombus and reciprocal triangle. This idea built on the geometric configures repetition to create an impres

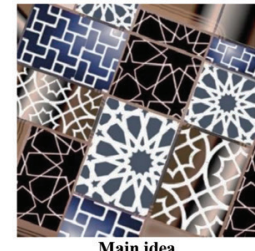

Main idea

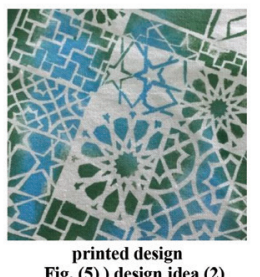

printed design
Fig, (5) ) design idea (2)

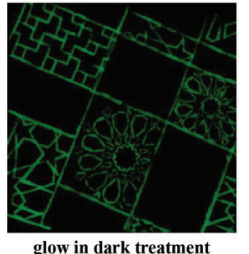

glow in dark treatment

sion the viewer can see that the design is integrated, this integration derived from the cohesion of configuration items after repeating it symmetrical which led to promote a sense of unity and interdependence of design elements.

The color:This work uses a variety group of the worm colors,also therepetition of the wide range colors in transparency, brightly, and gloomy creates a type of rhythmic harmony in the artistic work.

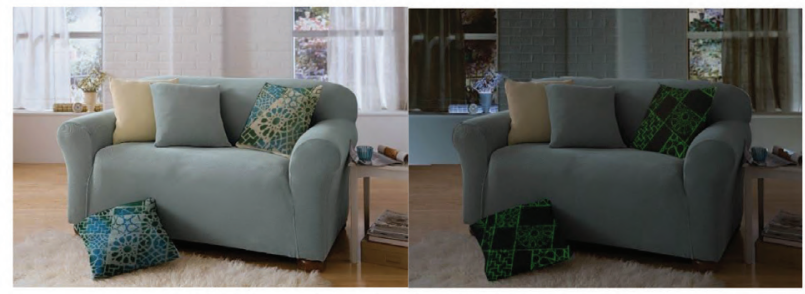

Fig. (6)Illustration of the 3D-simulation for Design (2)

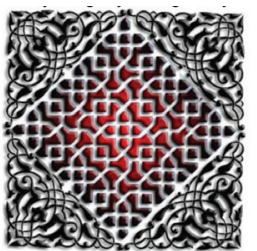

Main idea

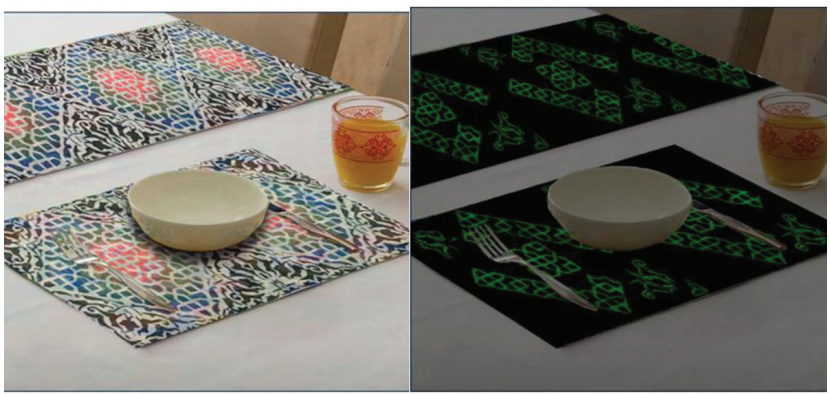

Fig. (8)Illustration of the 3D-simulation for Design (3)

2.2.4 Design Idea no. (4):This idea built oncombination of calligraphy and islamic geometric elements besidea big circlein design's center. This diversity and difference in the lines values and designing figures would generate to the recipient the sense of permanent movement and diversity

The color:Appear in this work, Achieving color contrast between white and black as well as warm and 
cold colors, which have been used to distinguish the figures to make the viewer able to realize it easily.

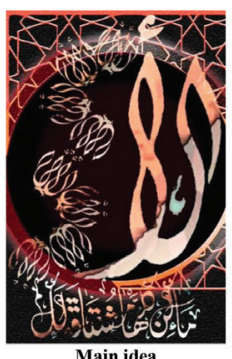

Main idea

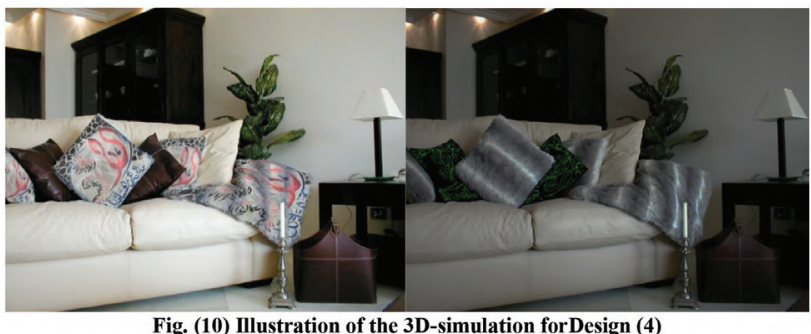

Fig. (10) Illustration of the 3D-simulation forDesign (4)

2.2.5 Design Idea no. (5): This idea built on Calligraphy, plant and geometric motifs which apply the diversity, this diversity and difference in the shapes values and designing units would generate to the recipient the sense of permanent movement and diversity.

The color:Appear in this work, the use of a group of harmonious colors which have been used to distinguish the figures to make the viewer able to realize it easily.

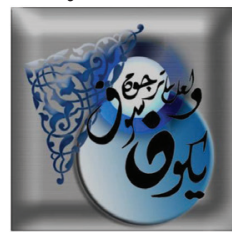

Main idea

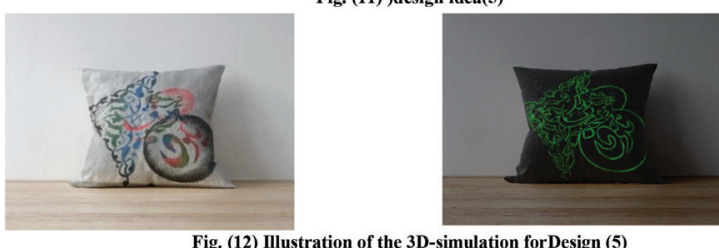

III. Result and Discussion

The result is divided into two parts: Firstly, the treated samples were evaluated to determine the best samples which fulfill the functional performance through studying the quality factor of each sample as shown in the table (2) \& (3). Secondly, evaluating the innovative designs by analysis the results of designed questionnaire.
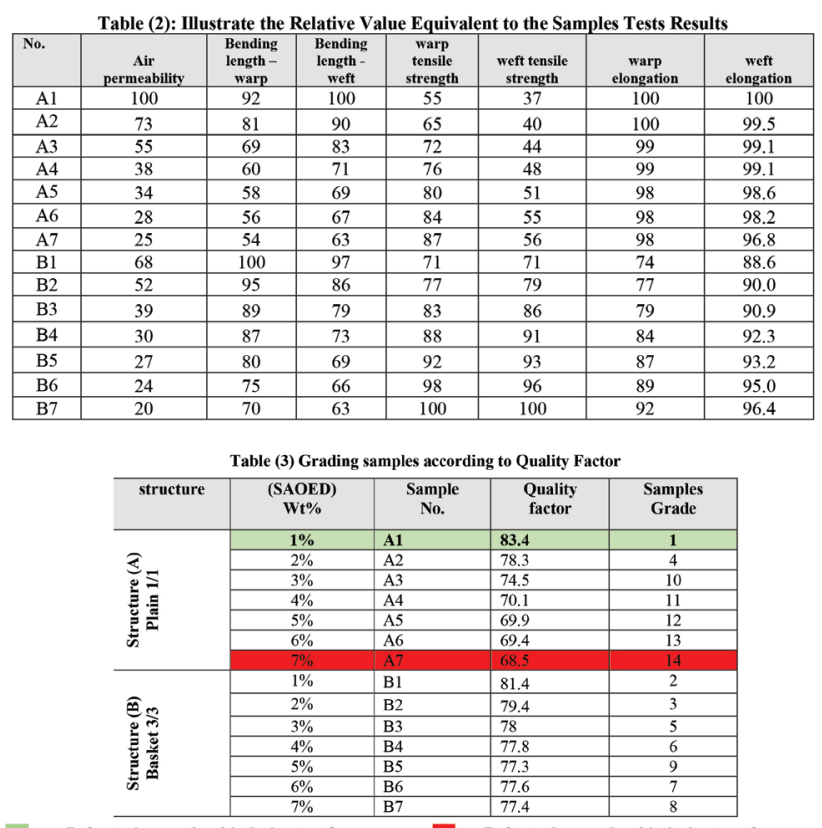

3.1 Evaluation of the best sample from (14 samples) 3.1.1 Quality Evaluation of treated fabrics with structure $(\mathrm{A})$

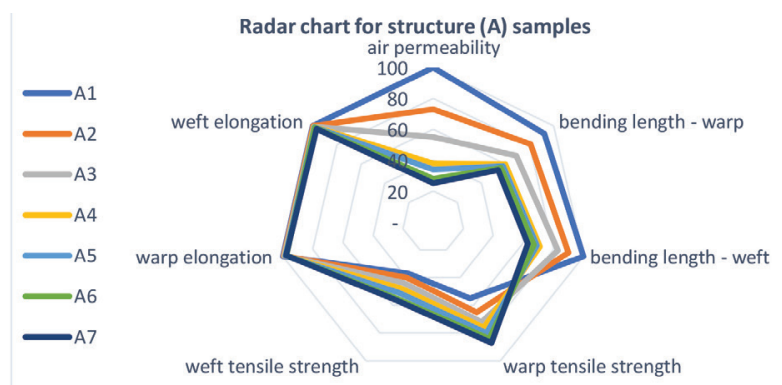

Fig. (13) Illustrate Radar Chart for the treated samples with structure (A)

From the analysis of figure (13), these items could be concluded:

The best sample performance evaluated by radar chart for the given properties is sample (A1) with the quality factor percentage $(83.4 \%)$. Whereas the lowest sample performance evaluated by radar chart for the given properties is sample (A7) with the quality factor percentage (68.5\%).

\subsubsection{Quality Evaluation of treated fabrics with} structure (B)

From the analysis of figure (14), these items could be concluded:

The best sample performance evaluated by radar chart for the given properties is sample (B1) with the quality factor percentage $(81.4 \%)$. Whereas the lowest sample performance evaluated by radar chart for the given 
properties is sample (B5) with the quality factor percentage $(77.3 \%)$.

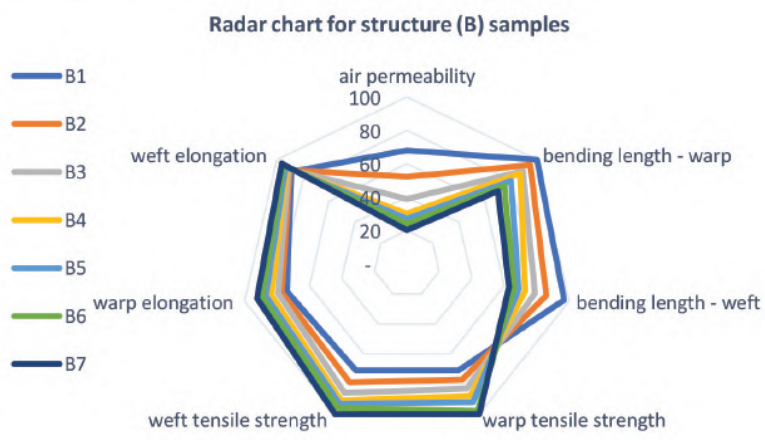

Fig. (14) Illustrate Radar Chart for the treated samples with structure (B)

3.1.3 Quality Evaluation of the (best \& least) treated fabrics.
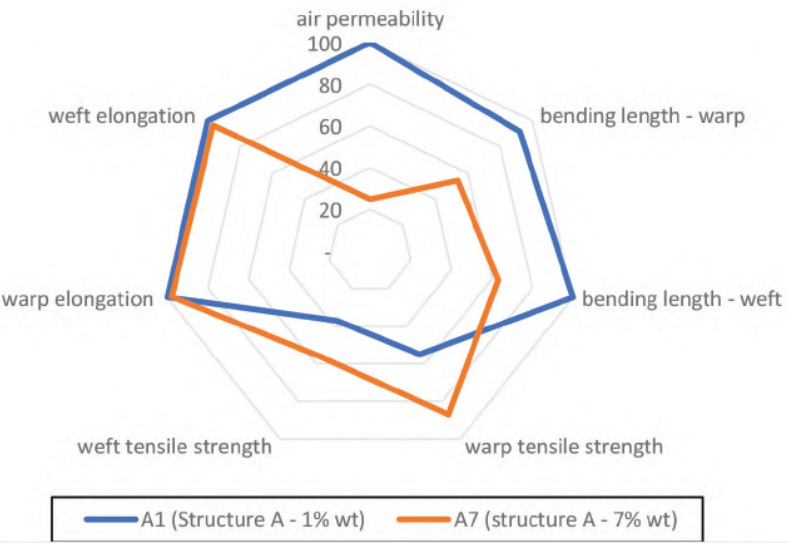

Fig. (15) Illustrate Radar Chart for the Samples with the (Best \& Least) Performance.

It was found from table (15) and figure (4) that the sample (A1) produced with structure (plain 1/1) and treated with (1\% wt.) concentration of strontium aluminate Phosphor has recorded the best performance according to quality factor. Whereas the sample (A7) produced with structure (plain 1/1) and treated with (7\% wt.) concentration of strontium aluminate Phosphor has recorded the least performance according to quality factor.

According to the quality factor grading of previous treated fabrics, research team decided that:

1.Tested the color fastness to rubbing for the sample (A1), addition to test the sample color fastness to washing

2.Applied the innovate designs inspired from Islamic art with the same specification of the sample (A1) which achieved a high functional property.

\subsubsection{Colorfastness to rubbing for the Sample with the best functional properties}

Table (4) \& (5) shows that the depth of color shade and fastness of the printed fabric is varied from excellent in dry case to very good in wet case.

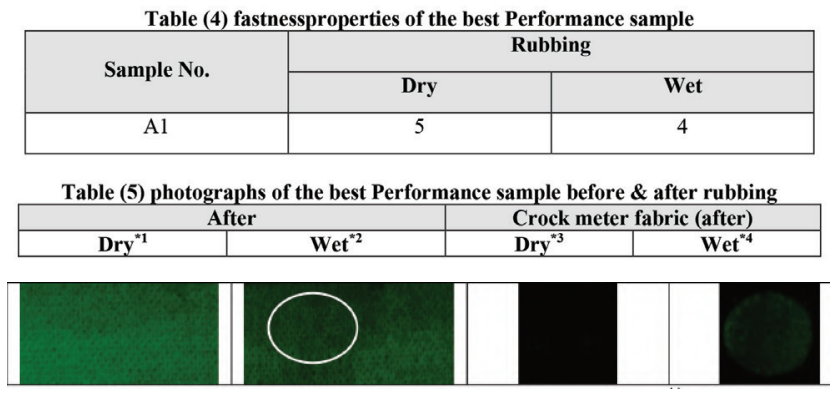

From table (5), it can be observed that, the treated sample after dry*1 rubbing more brighter than the sample after wet* 2 crocking. This is owing to the wetted crocking fabric (Wet*4)extracting some of (SAOED) particles from treated fabric which make the original sample become a little dull.

\subsubsection{Colorfastness to washing for the Sample with the best functional properties}

Table (6) shows the results of colorfastness to washing test carried out on the treated sample which recorded the best Performance in the quality factor grading. No differences were observed for the printed sample after washing.

Table (6) fastnessproperties of the best Performance sample

\begin{tabular}{|c|c|c|}
\hline \multirow{2}{*}{ Table (6) fastnessproperties of the best Performance sample } \\
\cline { 2 - 3 } & \multicolumn{2}{|c|}{ Washing } \\
\hline Sample No. & Alt.* & St.* \\
\hline Al & 4 & 4 \\
\hline
\end{tabular}

* Alt.: refer toalteration in color, St.: refer to staining on cotton.

\subsection{Analysis the results of designed questionnaire}

The research conducted questionnaire, intended to assess the designs provided to measure the quality of the designs provided and their suitability for employment as a glow in the dark upholstery fabrics , the results showed that:For first criterion, is obvious from table no. (7) and figure (16) that the weighted average was $(80 \%)$ confirms the importance of taking advantage of for the Islamic ornaments motifs as an inspiration source to enrich the printed furniture textile design, By referring to the weighting degree in the samples of designs the highest weighting was the design no.(2) by (89.3\%) followed by no.(1) by (82.1) $\%$ while the less percentage weighting come of design 
no. $(3,4)$ by $(75 \%)$
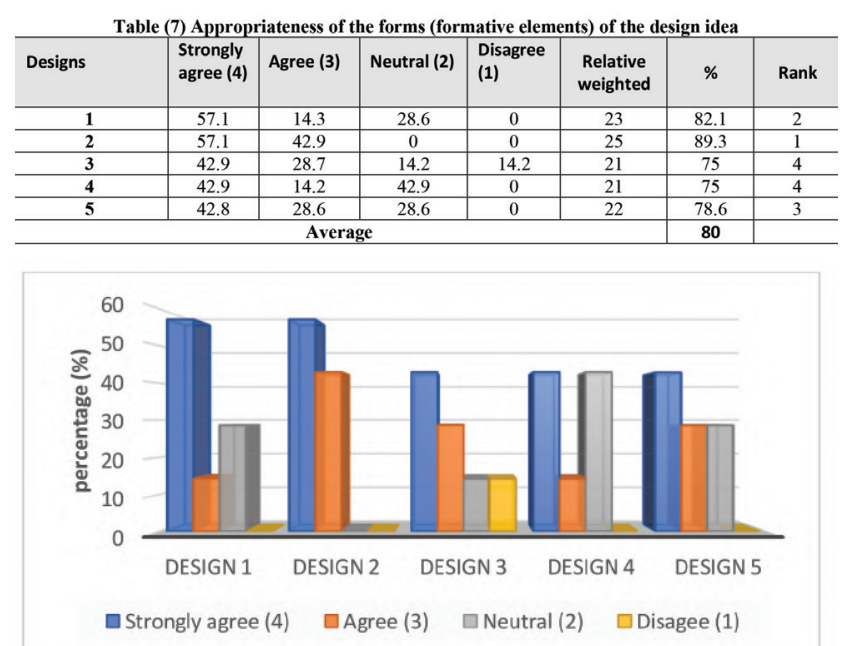

Fig. (16) Appropriateness of the forms of the design idea

For the second criterion, is obvious from table no. (8) and figure (17) that the weighted average was ( $82.8 \%)$ confirms The effect of using colors groups enrich the printed furniture textile design ideas, By referring to the weighting degree in the samples of designs the highest weighting was the design no.(2) by $(89.2 \%)$ followed by no.(1) by $(85.7 \%)$ while the less percentage weighting come of design no.(3)by (75\%).
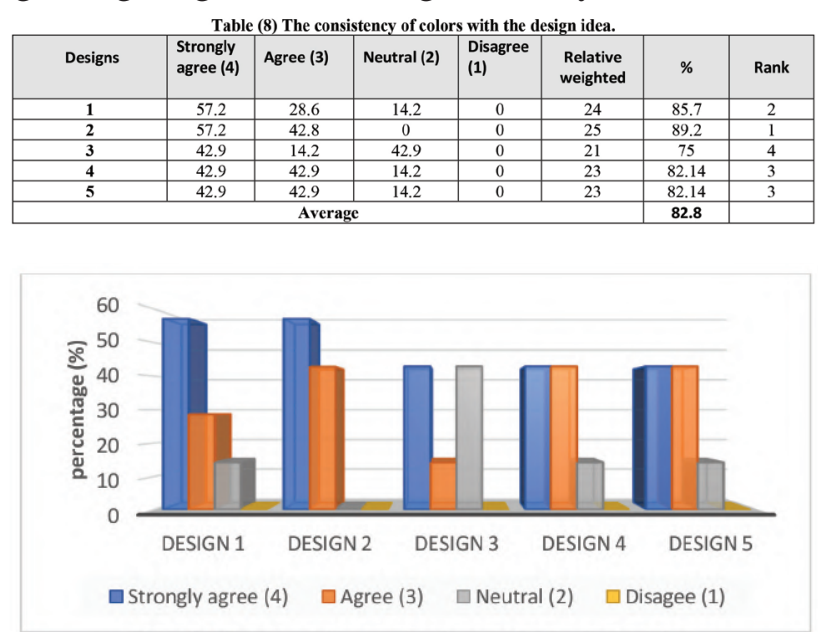

Fig.(17) The consistency of colors with the design idea.

Fig.(17) The consistency of colors with the design idea.

For the third criterion, is obvious from table no. (9) and figure (18) that the weighted average was (79.3\%) confirms the effect produced by the photo-luminescent printed fabric in darkness.By referring to the weighting degree in the samples of designs the highest weighting was the design no. (1.2.4) by $(82.14 \%)$ followed by no. $(3,5)$ by $(75 \%)$.
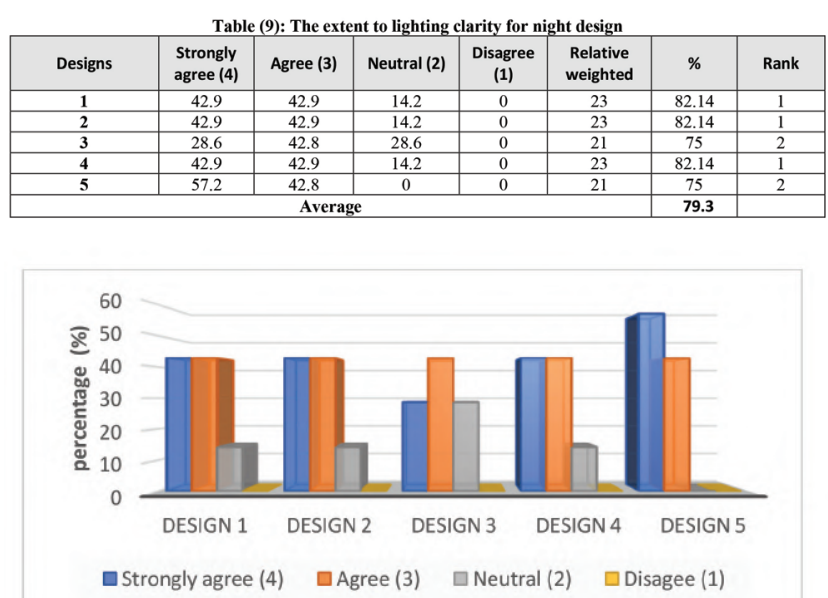

Fig.(18) The extent to lighting clarity for night design

For the fourth criterion, is obvious from table no. (10) and figure (19) that the weighted average was (85\%) confirms that the role of using photo-luminescent pigments to enrich the aesthetics of the design and enables the designer to achieve a variety of color combinations enriching the upholstery designs, By referring to the weighting degree in the samples of designs the highest weighting was the design no.(1) (92.8\%) followed by no.(5) by ( $89.3 \%)$ while the less percentage weighting come of design no.(3) by (75\%).
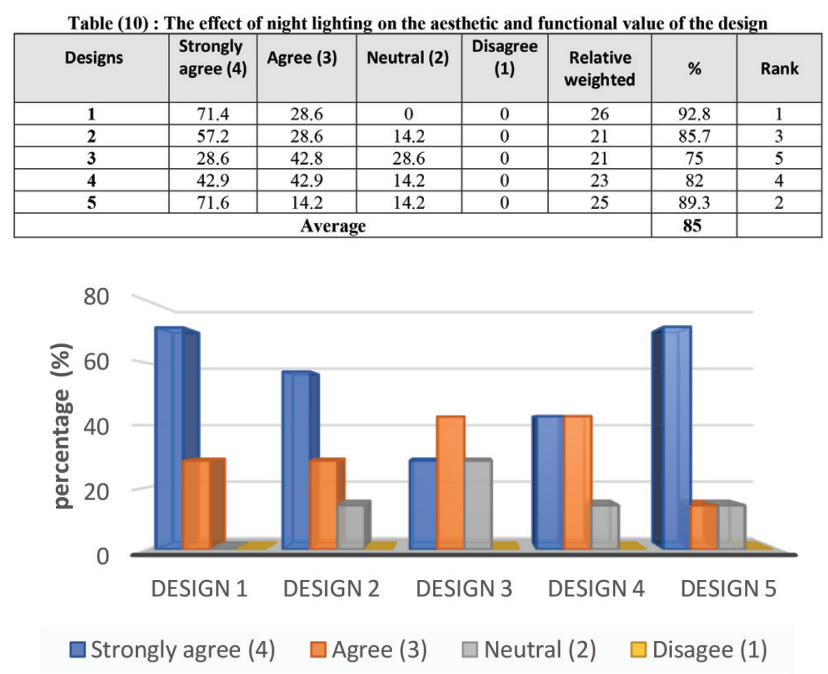

Fig.(19) Influence of night lighting design on the aesthetic and functional value

For the fifth criterion, is obvious from table no. (11) and figure (20) that the weighted average was $(80.7 \%)$ It appears that $80.7 \%$ of the research sample believe 
design ideas are appropriate for the proposed recruitment.By referring to the weighting degree in the samples of designs the highest weighting was the design no. $(1,2)$ by $(85.7 \%)$ followed by no. $(4,5)$ by $(82.1 \%)$ while the less percentage weighting come of design no.(3) by $(67.8 \%)$.
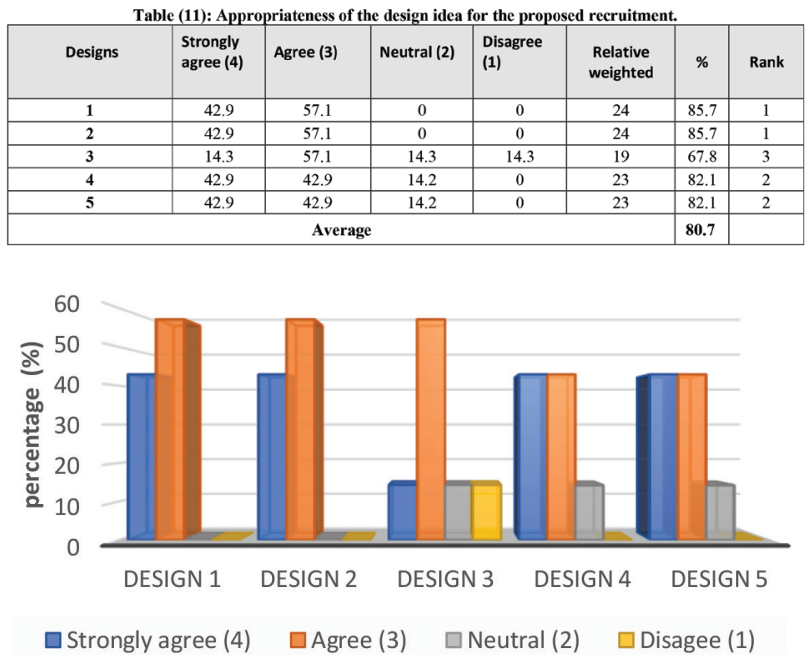

Fig. (20) Appropriateness of the design idea for the proposed recruitment

\subsubsection{Quality Evaluation of the best innovative de- sign according to questionnaire result}

Table (12): Grading of innovative designs according to questionnaire result

\begin{tabular}{|c|c|c|c|c|c|c|c|}
\hline \multirow[b]{2}{*}{ Designs } & \multicolumn{5}{|c|}{ Questionnaire } & \multirow[b]{2}{*}{ average } & \multirow[b]{2}{*}{ Grade } \\
\hline & $Q(1)$ & $Q(2)$ & $Q(3)$ & $Q(4)$ & $Q(5)$ & & \\
\hline 1 & 82.1 & 85.7 & 82.14 & 92.8 & 85.7 & 85.7 & 2 \\
\hline 2 & 89.3 & 89.2 & 82.14 & 85.7 & 85.7 & 86.4 & 1 \\
\hline 3 & 75 & 75 & 75 & 75 & 67.8 & 73.6 & 5 \\
\hline 4 & 75 & 82.14 & 82.14 & 82 & 82.1 & 80.7 & 4 \\
\hline 5 & 78.6 & 82.14 & 75 & 89.3 & 82.1 & 81.4 & 3 \\
\hline
\end{tabular}

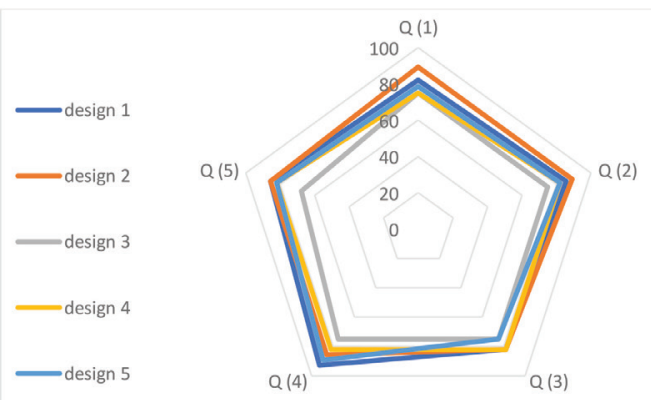

Fig. (21) Illustrate Radar Chart for the innovative design according to questionnaire result

\section{IV.Conclusion:}

The results obtained in the present work indicated that, fabric specification and mechanical properties changes as a different of concentration of strontium aluminate Phosphor used in printing paste. It was concluded from this study that, the air permeability and bending length of treated fabrics also tends to decrease with the increase of the (SAOED)concentration. The result of the experimental work and trials undertaken in this research evidently showed that the use of the structure (A) with $(1 \% \mathrm{wt}$.) concentration of strontium aluminate Phosphor has recorded the best performance according to quality factor. It fulfilled the objective of this research.

The study presented five main innovated solutions for woven upholstery design ideas inspired from Islamic art with its suggested usage to demonstrate the integration of aesthetic and functional values into interior design.

Producing upholstery fabrics designs glowing in dark by using strontium aluminate Phosphor is considered a technological method that enriches the aesthetics and function of the design and enables the designer to achieve a variety of colour combinations enriching the upholstery designs

\section{References:}

1.Edward Apau, design and production of innovative woven upholstery fabric designs using the broadloom, M.sc thesis, Department of Industrial Art, Kwame Nkrumah University of Science and 2013

2.Zaki Mohamed Hassan, the Islamic arts, Dar Nawabgh al fekr, 1999

3.Eva Wilson, Islamic decorations and drawings, translation Amal Maroud, Dar kabes for printing and publishing. 2004

4.Mary and James G. Wallach Foundation, , Islamic Art and Geometric Designs, The Metropolitan Meuseum of Art, 2004

5.Bernard Denvir, Impressionism the painters and the paintings, studio editions, London, 1991

6.Bernard O' Kane, The Treasures of Islamic Art in the Museums of Cairo, The American University Press, Cairo. 2006

7.Ebrahimzade, M. R. M. Mojtahedi, R. Semnani Rahba Study on characteristics and afterglow properties of luminous polypropylene/ rare earth strontium aluminate fiber, Journal of Materials Science: Materials in Electronics, Volume 28, Issue 11, pp 81678176, 2017.

8.Richa Sharma and Nilanjana Bairagi, The Role of Photoluminescent Pigments in Textiles, Trends in Textile Engineering \& Fashion Technology journal, vol2 , issue 2, pp 164: 167, 2018 9.Tawfik Khattab, Mohamed Fawzy Rehan, Yousry Hamdy, and Tharwat Ibrahim Shaheen, Facile development of photoluminescent textile fabric via spray-coating of Eu (II)-doped strontium aluminate, Industrial \& Engineering Chemistry Research, 2018 10.Fang Gao1, Zhaoxian Xiong2, Hao Xue2 and Yongxi Liu2, Improved performance of strontium aluminate luminous coating on the ceramic surface , Journal of Physics: Conference Series, 2017

11.Tawfik A. Khattab $\square$, Mohamed Rehan $\square$, Tamer Hamouda, Smart textile framework: Photochromic and fluorescent cellulosic fabric printed by strontium aluminate pigment, Carbohydrate Polymers 195 (2018) 143-152

12.Leah Bergman, Jeanne L. McHale, Handbook of Luminescent Semiconductor Materials, CRC Press, 2011

13. Patel, Nikita. H., Preparation characterization of undoped and doped cds nanoparticles, Ph. D. Thesis, Department of Physics, Sardar Patel University, 2015

14. ISO 105-X12 "Standard test method for Colour fastness to rubbing of textile fabrics"

15. ISO 105-C02 "Standard test method for Colour fastness to washing of textile fabrics" 